\begin{tabular}{|} 
Ambiente \& Água - An Interdisciplinary Journal of Applied Science \\
ISSN 1980-993X - doi:10.4136/1980-993X \\
www.ambi-agua.net \\
E-mail: ambi-agua@agro.unitau.br
\end{tabular}

\title{
Condições físico-químicas e biológicas em águas superficiais do Rio Tapajós e a conservação de Floresta Nacional na Amazônia, Brasil
}

\author{
doi: 10.4136/ambi-agua.1304
}

Received: 05 Feb. 2014; Accepted: 13 Sep. 2014

\author{
Sarah Suely Alves Batalha ${ }^{1 *}$; Lucieta Guerreiro Martorano ${ }^{2}$; \\ Adriele Giaretta Biase ${ }^{3}$; Gundisalvo Piratoba Morales ${ }^{1}$; \\ Altem Nascimento Pontes ${ }^{1}$; Leonardo Sousa dos Santos ${ }^{4}$ \\ ${ }^{1}$ Universidade do Estado do Pará (UEPA), Belém, PA, Brasil \\ ${ }^{2}$ Empresa Brasileira de Pesquisa Agropecuária (EMBRAPA) Amazônia Oriental, Belém, PA, Brasil \\ ${ }^{3}$ Universidade de São Paulo (USP), Piracicaba, SP, Brasil \\ ${ }^{4}$ Universidade Federal Rural da Amazônia (UFRA), Belém, PA, Brasil \\ "Autor correspondente: e-mail: ssa.batalha @ gmail.com, \\ lucieta.martorano@embrapa.br, adrielegbiase@gmail.com, \\ gundymorales@yahoo.com.br, altempontes@hotmail.com, \\ leonardocbmpa@yahoo.com.br
}

\section{RESUMO}

A bacia amazônica detém uma grande quantidade de água que deve ser conservada para atender as necessidades desta e das futuras gerações. O objetivo deste trabalho foi avaliar condições físico-químicas e biológicas em águas superficiais do Rio Tapajós como indicadores da conservação de Floresta Nacional na Amazônia. Para a tomada de decisão quanto ao período de coleta levou-se em consideração apoio logístico e financeiro, sendo possível as coletas na época de menor oferta pluvial com base em informações climáticas na Flona e seu entorno. As coletas no rio Tapajós ocorreram em áreas de influência quanto ao uso e ocupação do solo. Foram realizadas avaliações no local, bem como análises em laboratório. Os resultados apontaram que dezembro de 2012 foi mais chuvoso em relação a climatologia. Os resultados do Índice de Qualidade de Água (IQA) indicaram o predomínio na qualidade "boa" a "ótima", nas quais as faixas variaram entre $70<\mathrm{IQA} \leq 90$ e $90<$ IQA $\leq 100$, totalizando 70,0\% das amostras coletadas. Os balneários de Alter do Chão e Pindobal foram os que apresentaram valores elevados de coliformes termotolerantes, possivelmente devido os efeitos antrópicos que poderiam ser mitigados com práticas de turismo adequadas. O maior IQA e a maior transparência da água, identificados próximo a Tauarí, evidenciaram efeitos mínimos nas águas superficiais pela ação antrópica nessa localidade. Conclui-se que os corpos hídricos são sensíveis a alterações na cobertura da terra e estas podem ameaçar à manutenção de áreas de uso conservacionista.

Palavras-chave: qualidade de água, unidade de conservação. 


\title{
Physico-chemical and biological conditions in surface waters of the Tapajós River and the conservation of the National Forest in the Amazon, Brazil
}

\begin{abstract}
The Amazon Basin has a large amount of water that must be conserved to meet the needs of this and future generations. This study evaluated evidence of the effects of human disturbance in the Tapajos National Forest and its surroundings using physicochemical and biological variables in surface waters as indicators. In order to accomplish this, we first analyzed the data series of precipitation in the region. Samples were collected from the Tapajos River in areas influenced by land use and occupation. We made on-site assessments and collected samples for laboratory analysis. Rainfall in December 2012 was higher than the climatology indicated. The results of the Water Quality Index (WQI) indicated the predominance of the "good" to "great"; its values ranged between $70<\mathrm{WQI} \leq 90$ and $90<\mathrm{WQI} \leq 100$, in $70.0 \%$ of the samples collected. The balnearies Alter do Chão and Pindobal had the highest levels of fecal coliform, possibly due to anthropogenic effects that could be mitigated by adequate tourist practices. The highest WQI and greater transparency of the water near Tauari, showed minimal effects of human activities in nearby surface waters. It is concluded that water bodies are sensitive to changes in land use and those changes may threaten the maintenance of conservation areas.
\end{abstract}

Keywords: conservation unit, water quality.

\section{INTRODUÇÃO}

A conservação de áreas de florestas na Amazônia vai além dos discursos idealistas, pois esses ambientes fornecem serviços ambientais essenciais que vão desde a manutenção do ciclo hidrológico e da biodiversidade até a garantia de oferta em possíveis mercados de carbono (Fearnside, 2013).

O Brasil possui condições ambientais favoráveis que o coloca em vantagens frente aos recursos naturais disponíveis, principalmente quanto ao aspecto bacias hidrográficas, como é o caso da Bacia Amazônica. Com isso, o uso conservacionista dos recursos hidrológicos demanda de investigações para apontar áreas críticas à preservação de ecossistemas aquáticos (Artaxo, 2007).

Um corpo hídrico em equilíbrio ecológico, que garanta a saúde e o bem-estar humano, depende que parâmetros físicos, químicos e biológicos estejam dentro de um nível de qualidade avaliado por condições e padrões específicos que assegurem seus usos preponderantes, conforme Resolução $\mathrm{n}^{\circ}$ 357, do Conselho Nacional do Meio Ambiente (CONAMA, 2005). A Companhia Ambiental do Estado de São Paulo (CETESB, 2012) destaca, por exemplo, que variações bruscas de temperatura em uma faixa de 3,0 a $4,0^{\circ} \mathrm{C}$ no mesmo dia podem ser letais para algumas espécies e que condições de $\mathrm{pH}$ podem corresponder à formação de um ecossistema mais diversificado tanto em meios aeróbicos quanto em anaeróbicos (CETESB, 2006).

Silva et al. (2008) apontam 6 (seis) parâmetros fundamentais: temperatura, pH, turbidez, condutividade elétrica, oxigênio dissolvido e sólidos em suspensão. Na Amazônia, em específico, os ecossistemas aquáticos são importantes tanto para o ciclo da água regional, 
quanto para a energia hidrelétrica e utilizações da água em outras regiões do globo (Fearnside, 2004; 2013).

As avaliações de qualidade hídrica expressam o estado de uso e conservação em uma bacia hidrográfica e, portanto, auxiliam na tomada de decisão sobre a manutenção do equilíbrio ecológico. Espera-se que áreas legalmente protegidas na Amazônia possam fornecer bens e serviços ecossistêmicos às populações, bem como manter a biodiversidade. No entanto, percebe-se que muitas Unidades de Uso Sustentável estão sendo ameaçadas com perdas de suas áreas demarcadas, como é o caso da Floresta Nacional do Tapajós, localizada a oeste do estado do Pará, na Amazônia brasileira. Observa-se que, desde a sua criação na década de 70 do século passado (Brasil, 1974), houve redução de aproximadamente 4\% do território demarcado. A recente retirada do município de Aveiro e da comunidade São Jorge (Brasil, 2012) reforçam que processos históricos associados a possíveis pressões decorrentes da expansão da fronteira agrícola na região, por exemplo, podem ameaçar a sustentabilidade se os sistemas de produção não utilizarem práticas conservacionistas, conforme ressaltam Martorano et al. (2004; 2012). Os processos de degradação das terras estão associados a fatores edáficos, climáticos e antrópicos (Manzatto et al., 2002).

A análise integrada dos sistemas aquático e terrestre, no espaço e no tempo, permite concluir que a degradação da qualidade da água se deve às alterações no uso e cobertura da terra e ao aumento populacional, traduzidos em fontes difusas e pontuais de poluição (Prado e Novo, 2006). Ao avaliarem constituintes oticamente ativos na água, usando imagens hiperespectrais, Rudorff et al. (2006) identificaram três padrões de variação temporal e espacial no período de cheia e de vazante em águas brancas do Amazonas e águas claras do Tapajós, ou seja, aumento e reduções nas concentrações de matéria inorgânica em suspensão nos rios e de ocorrência de fitoplânctons nos lagos, refletindo na qualidade da água desses rios.

Quanto ao diagnóstico de qualidade de água, destacam-se na Amazônia os trabalhos de Siqueira et al. (2012) e Alves et al. (2012). No primeiro, os autores ressaltam a influência da expansão urbana ao longo do rio Parauapebas em áreas próximas às reservas de mata ciliar. $\mathrm{O}$ segundo trabalho, realizado no rio Arari, na Ilha do Marajó, revelou um processo de eutrofização natural, com fontes de contaminação antrópica incipientes, o que, no entanto, não anula o alerta em um processo de longo prazo.

Nesse contexto, objetivou-se avaliar condições físico-químicas e biológicas em águas superficiais para apontar evidências de uso conservacionista em áreas no entorno da Flona Tapajós (oeste do estado do Pará) para subsidiar possíveis estratégias sustentáveis na região de estudo.

\section{MATERIAL E MÉTODOS}

\section{1. Área de estudo}

A Unidade de Uso Sustentável, Floresta Nacional do Tapajós, está localizada a oeste do estado do Pará, com coordenadas geográficas $2^{\circ} 45^{\prime}$ a $4^{\circ} 10^{\prime} \mathrm{S}$ e $54^{\circ} 45^{\prime}$ a $55^{\circ} 30^{\prime} \mathrm{W}$. A Floresta Nacional do Tapajós é a $13^{\mathrm{a}}$ Flona criada no país em um total de 66 existentes em 2004 e, a segunda criada na região Norte, bem como a segunda no Estado do Pará. Pela Lei Federal $\mathrm{n}^{\mathrm{o}} 12.678$ de junho de 2012, a área da Flona Tapajós foi reduzida em aproximadamente $4 \%$ de seu tamanho original. Estas áreas passaram a ser consideradas como áreas de amortecimento desta UC. Esta redução pode acarretar em possíveis ameaças na manutenção de bens e serviços que a Flona oferece às populações, provocando com o passar dos anos, alterações no modo de vida das comunidades da Flona e entorno, aumentando assim as pressões nesta unidade de conservação. De acordo com o Sistema Nacional de Unidades de 
Conservação (SNUC, 2002), uma Floresta Nacional (ou Flona) caracteriza-se como uma área com cobertura florestal com predominância de espécies nativas e seu objetivo básico é o uso múltiplo sustentável dos recursos florestais e a pesquisa científica.

Com base no Plano de Manejo da Flona Tapajós, existe a integração de diferentes agrupamentos humanos que desenvolvem atividades tradicionais de sistema de produção, combinando cultivo de roçados, extrativismo, manejo agroflorestal, caça, criação de pequenos animais e pesca. As populações integradas são: comunidades ribeirinhas, indígenas, assentamentos e posseiros (IBAMA, 2004), totalizando, atualmente 25 (vinte e cinco) comunidades, das quais 23 (vinte e três) estão situadas na zona ribeirinha.

Quanto ao acesso, este pode ser por vias fluviais, principalmente pelo rio Tapajós, ou terrestres, através da Rodovia BR-163 (Cuiabá-Santarém).

A rede hidrográfica da Flona caracteriza-se pela divisão de calhas do rio Tapajós, além de abrigar a nascente do rio Moju, afluente do rio Curuá-Una, cuja foz é no rio Amazonas, na região urbana de Santarém.

\subsection{Levantamento de dados de campo}

Tendo em vista as dificuldades financeiras e a distância entre Belém e a área de estudo, localizada próximo a Santarém, decidiu-se planejar as coletas de campo na Flona Tapajós no período de menor oferta pluvial na região. Ressalta-se que esses pressupostos metodológicos foram apenas em função de custos e apoio logístico.

Para subsidiar as avaliações do regime pluvial, utilizou-se uma série histórica de 40 anos (1972 a 2012) do município de Belterra (2,63 ${ }^{\circ}$ Latitude $S ; 44,95^{\circ}$ Longitude W e 155,74 metros de Altitude), a partir dos dados meteorológicos disponibilizados pelo Instituto Nacional de Meteorologia (INMET). Também foram utilizados dados das Normais Climatológicas (INMET, 2009), bem como os dados referentes ao ano de 2012, gentilmente cedidos pelo INMET, utilizando acesso permitido no Banco de Dados Meteorológicos para Ensino e Pesquisa (BDMEP). Assim sendo, no período de menor oferta pluvial procurou-se identificar ao longo do rio Tapajós elementos que apontassem evidências do estado de conservação na Unidade de Uso Sustentável (Flona).

O trabalho ocorreu após a capacitação da equipe, contando com o planejamento, separação de materiais e definição de variáveis investigadas a campo. Nessa etapa foram listados os itens necessários para garantir o sucesso do trabalho de campo. Cada item foi cuidadosamente conferido (check-list) para preservação, manuseio e transporte das amostras, bem como as possibilidades de análises in situ e ex situ dentro dos prazos de validade, seguindo os protocolos de amostragem e análise de corpos d'água, padronizada pelo Standard Methods for Water and Wastewater (APHA, 2005) e regulamentados no Brasil pela Companhia de Tecnologia de Saneamento Ambiental do Estado de São Paulo (CETESB, 2011).

O período de viagem foi de 17 a 20 de dezembro de 2012. Nos dias anteriores fez-se reconhecimento e identificação de uso e cobertura do solo, utilizando o GPS (Global Position System) da marca Garmin Etrex de 12 canais, do tipo métrico de navegação, com precisão planimétrica aceitável. Essas informações foram coletadas via terrestre, ao longo da Rodovia BR-163, e via fluvial, no dia de coletas para compor a base de dados no âmbito do Projeto ROBIN (Role of Biodiversity in Climate Change Mitigation), no qual a pesquisa foi inserida.

Os dados obtidos com o GPS foram descarregados e plotados pela equipe do Projeto ROBIN. As informações dos locais de coletas foram identificadas no mapa de localização, contando-se com colaboração da equipe de geoprocessamento que utilizou a ferramenta Quantum Gis 2.0, licenciado pela General Public License. Os pontos foram associados à base de dados agregados do Instituto Brasileiro de Geografias e Estatísticas (IBGE, 2013). 
As coletas de água no rio Tapajós, no entorno da Flona, ocorreram no dia 19 de Dezembro. As amostras foram armazenadas, transportadas para Belém e levadas aos laboratórios para análise dos parâmetros. Foram selecionados 10 (dez) pontos de coleta no rio Tapajós e, em cada ponto, foram retiradas 4 (quatro) alíquotas, totalizando 40 (quarenta) amostras.

Neste contexto, a campanha iniciou às 6 h00 do dia 19 de dezembro de 2012 com a saída das docas da cidade de Santarém, no entanto a primeira coleta só ocorreu após as 13h00, devido à distância da Flona e o período de reconhecimento via fluvial. A conclusão com retorno à Santarém foi às $20 \mathrm{~h} 00$ do mesmo dia.

Ressalta-se que a equipe contou com o apoio oficial do $4^{\circ}$ Grupamento Bombeiros Militar (Santarém, Pará), que forneceu suporte de pessoal e lancha para deslocamento no rio Tapajós.

As amostras de água foram coletadas em frascos de polietileno quimicamente inertes com tampas autolacráveis e frascos para oxigênio dissolvido, de vidro borossilicato com tampa esmerilhada e estreita (pontiaguda) e foram transportadas em caixas térmicas lacradas e mantidas em conservação a uma temperatura de $\pm 4,0^{\circ} \mathrm{C}$.

Com a utilização de um termômetro de mercúrio aferiu-se a temperatura $\left({ }^{\circ} \mathrm{C}\right)$ superficial em cada ponto de coleta. Além disso, utilizou-se o disco de Secchi para determinar a coluna de transparência da água. O disco circular possui quatro divisões intercaladas com cores pretas e brancas e um cabo graduado para auxiliar na identificação da profundidade de visualização do disco. De acordo com a CETESB (2011), a medida de transparência pode ser considerada uma variável de qualidade, uma vez que estima a profundidade da zona fótica, ou seja, a profundidade de penetração vertical da luz solar na coluna d'água, que indica o nível da atividade fotossintética naquele corpo hídrico.

Os demais parâmetros ( $\mathrm{pH}$, Sólidos Totais, Fósforo total, Oxigênio Dissolvido, Demanda Bioquímica de Oxigênio, Turbidez, Nitrogênio Total, Coliformes Totais, Coliformes Termotolerantes e Condutividade) foram determinados em laboratório.

Deu-se prioridade às análises que demandavam prazo de conservação menor que 24 horas, como: Demanda Bioquímica de Oxigênio (DBO), Coliformes Totais e Termotolerantes e Nitrogênio Total (Nt).

Destaca-se que o as amostras para Oxigênio Dissolvido (OD) foram fixadas, a campo, com $2 \mathrm{~mL}$ de Iodeto de Azida e $2 \mathrm{~mL}$ de Sulfato de Manganês, sendo levadas ao laboratório onde foram retiradas alíquotas para determinação do oxigênio dissolvido pelo método titulométrico de Winkler (Gatti et al., 2002), como descrito em APHA (2005). As alíquotas foram rigorosamente codificadas em consonância com a respectiva marcação em GPS e o horário da coleta, além de serem detalhadas em fichas individuais que incluíam as coordenadas, condições de tempo como chuva, nebulosidade e temperatura do ar, no dia da coleta e nas últimas vinte e quatro horas.

Os dados adquiridos por via terrestre e fluvial foram georreferenciados e geraram o mapa de localização (Figura 1) da região contemplada nas ações desta pesquisa. Observa-se que as amostras foram coletadas no rio Tapajós próximo a comunidades e regiões de potencial atrativo turístico.

Um corpo hídrico pode também ser caracterizado por meio da inferência de um indicativo de qualidade. O Índice de Qualidade de Água (IQA) foi desenvolvido pela National Sanitation Foundation (NSF), dos Estados Unidos, e sintetiza em um fator único global a qualidade de água, a partir da ponderação de nove parâmetros (Coliformes Termotolerantes, pH, DBO, Nitrogênio e Fósforo total, Temperatura, Turbidez, Sólidos e Oxigênio Dissolvido) considerados mais representativos para a caracterização da qualidade da água (Von Sperling, 2007). No Brasil, o IQA da NSF foi modificado pela CETESB, que substituiu o Nitrato por Nitrogênio total e amplia as faixas nacionais de tolerância de níveis de IQA. 


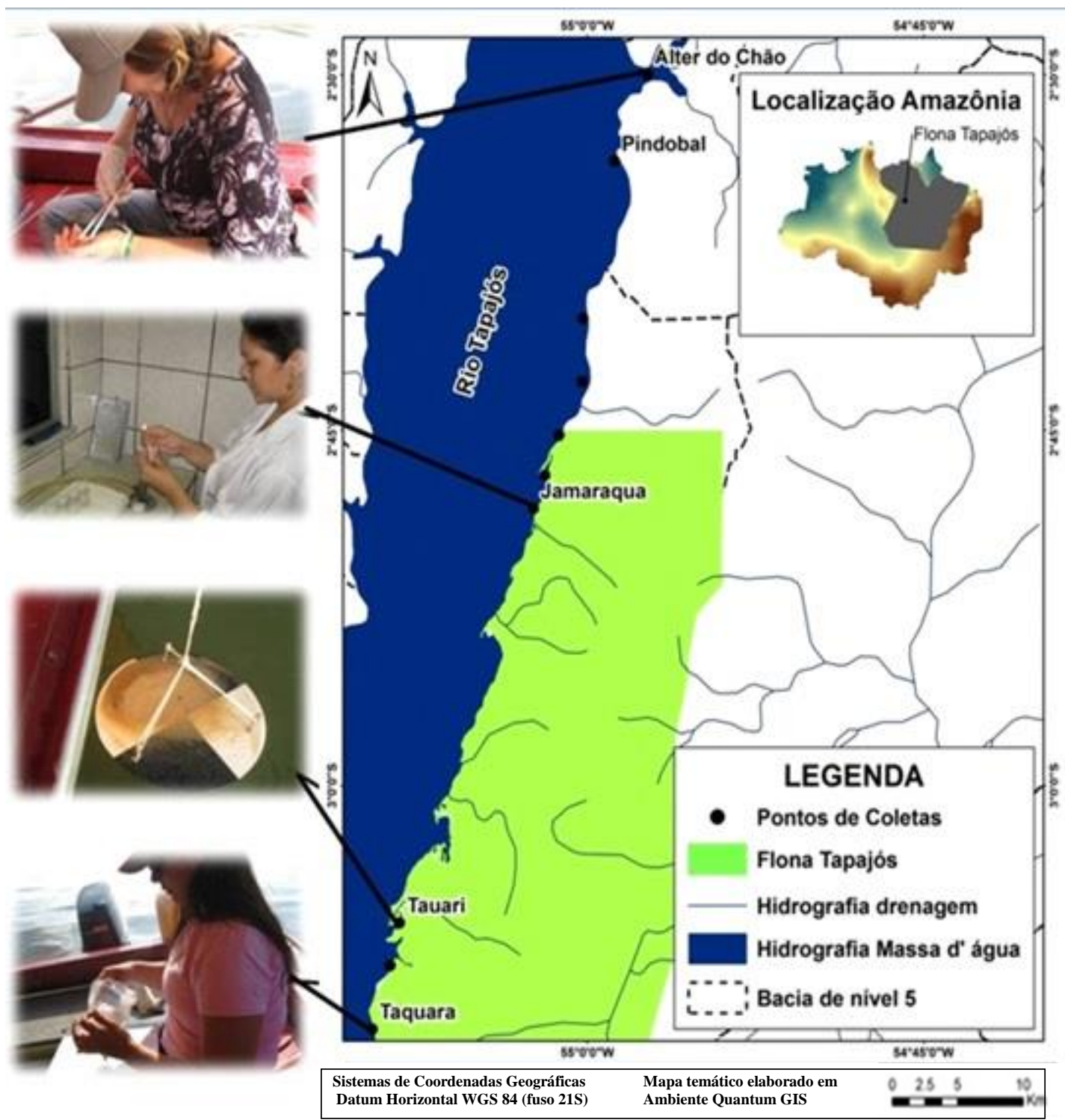

Figura 1. Localização dos pontos de coleta no rio Tapajós - Amazônia, Brasil.

A cada parâmetro aplica-se um peso e o resultado das equações das curvas de qualidade são calculados a partir da Equação 1, que é o produtório das notas individuais de cada parâmetro, elevada aos respectivos pesos:

$$
I Q A=\prod_{i=1}^{n} q_{i}^{w 1}
$$

em que,

IQA representa o Índice de Qualidade das Águas (número entre 0 e 100);

$\mathrm{q}_{\mathrm{i}}$ é a qualidade do i-ésimo parâmetro, um número entre 0 e 100, obtido da respectiva "curva média de variação de qualidade", em função de sua concentração ou medida;

$\mathrm{W}_{\mathrm{i}}$ é o peso correspondente ao i-ésimo parâmetro, um número entre 0 e 1 , atribuído em função da sua importância para a conformação global de qualidade e

i refere-se ao número do parâmetro, variando de 1 a 9 , ou seja, o número de parâmetros que compõem o IQA. 
Os valores dos índices variam entre 0 e 100 e a qualidade da água é classificada por faixas de IQA (Tabela 1).

Tabela 1. Faixas para classificação do IQA, segundo NSF e CETESB.

\begin{tabular}{lllc}
\hline & Nível & Cor & Faixa de IQA \\
\hline & Excelente & Azul & $90<\mathrm{IQA} \leq 100$ \\
IQA & Bom & Verde & $70<\mathrm{IQA} \leq 90$ \\
NSF & Médio & Amarela & $50<\mathrm{IQA} \leq 70$ \\
& Ruim & Laranja & $25<\mathrm{IQA} \leq 50$ \\
& Muito Ruim & Vermelha & $0<\mathrm{IQA} \leq 25$ \\
\hline & Ótima & Azul & $80 \leq \mathrm{IQA} \leq 100$ \\
IQA & Boa & Verde & $52 \leq \mathrm{IQA}<80$ \\
CETESB & Aceitável & Amarela & $37 \leq \mathrm{IQA}<52$ \\
& Ruim & Laranja & $20 \leq \mathrm{IQA}<37$ \\
& Péssima & Vermelha & $0 \leq \mathrm{IQA}<20$ \\
\hline
\end{tabular}

Fonte: Von Sperling (2007).

\subsection{Análise estatística descritiva, agrupamentos e componentes principais}

As análises estatísticas foram realizadas com o apoio de parceiros científicos da ESALQ/USP, que utilizaram o programa SAS (SAS, 2008). As variáveis usadas no tratamento estatístico foram: $\mathrm{pH}$, Sólidos Totais $\left(\mathrm{mg} \mathrm{L}^{-1}\right)$, Fósforo total $\left(\mathrm{mg} \mathrm{L}^{-1}\right)$, Oxigênio Dissolvido (mg L $\left.\mathrm{L}^{-1}\right)$, Demanda Bioquímica de Oxigênio $\left(\mathrm{mg} \mathrm{L}^{-1}\right)$, Turbidez (UNT), Temperatura da água $\left({ }^{\circ} \mathrm{C}\right)$, Nitrogênio Total $\left(\mathrm{mg} \mathrm{L}^{-1}\right)$, Coliformes Termotolerantes e Coliformes Totais (NMP $\left.100 \mathrm{~mL}^{-1}\right)$, Transparência $(\mathrm{cm})$, Condutividade $\left(\mu \mathrm{S} \mathrm{cm}^{-1}\right)$ e Índice de Qualidade de Água (IQA).

Destaca-se que foram aplicados dois métodos de análises multivariadas: agrupamento (clusters) e análise de componentes principais. Os componentes principais foram obtidos por meio da matriz de correlação para que não houvesse predominância em relação às variáveis com maiores variâncias. A partir da matriz de correlação foram obtidos os autovalores e autovetores, os quais indicam o sentido da rotação dos eixos das coordenadas definidos pelas variáveis originais. Os autovalores representam as variâncias destes novos eixos coordenados. $\mathrm{O}$ número de componentes principais retidos na análise foi definido com base em dois discernimentos: pela porcentagem cumulativa da explicação da variação total e pela representação gráfica do Screen plot (gráfico não apresentado nesse trabalho). A obtenção dos componentes principais é descrita por Manly (2004) e Mingoti (2005).

Após análise dos componentes principais foram representadas graficamente em um plano bidimensional, o Biplot e o Triplot, buscando identificar as observações discrepantes e o comportamento da correlação entre as variáveis, para observar as associações entre os pontos amostrais e as variáveis, bem como indicar quais variáveis são responsáveis pela explicação de cada ponto (Ferreira, 2011).

$\mathrm{Na}$ análise dos clusters utilizaram-se procedimentos hierárquicos, o cálculo das distâncias entre os objetos foi realizado com o conjunto de dados padronizados com o objetivo de dar um peso igual a cada um dos atributos. 


\section{RESULTADOS E DISCUSSÃO}

Ao avaliar o regime pluvial mensal em Belterra (Figura 2) observa-se que de julho a dezembro existe a menor oferta pluvial. Observando a série histórica de 1972 a 2012, as médias pluviais foram superiores aos totais de precipitação ocorridos nos meses de fevereiro a junho e agosto a novembro de 2012. Os demais meses, em 2012, foram mais pluviosos em relação à série histórica. Ao comparar com o volume precipitado, com base nas normais climatológicas, nota-se que na série de 40 anos a pluviosidade segue o padrão semelhante na maioria dos meses, com exceção de maio e dezembro. Nesses meses ocorrem as maiores flutuações no regime pluvial, expressas pelo desvio padrão. Em dezembro, a média de chuvas é da ordem de 150,0 mm, e em 2012 choveu 250,0 mm, apontando uma oferta pluvial de 100,0 mm acima da média da série histórica de 40 anos, bem como em termos de normais climatológicas.

De dezembro a maio as chuvas mensais ultrapassam os $100 \mathrm{~mm}$ mensais sendo que janeiro a abril o total varia entre 150,0 a $320,0 \mathrm{~mm}$. A climatologia aponta que valores mais elevados, em termos de cotas pluviais, ocorrem em março. Em termos de quantidade de água precipitada, o mês de dezembro de 2012 foi mais pluvioso em relação às normais climatológicas e à série de 40 anos analisada.

Antes da coleta (19/12/2012), na estação meteorológica de Belterra, houve um período de 15 dias sem registros de chuva, indicando condições propícias às avaliações em águas superficiais, no Rio Tapajós, conforme os pressupostos metodológicos da pesquisa. Ao observar os valores diários, identificou-se que no dia 01 de dezembro choveu $72,8 \mathrm{~mm}$, prolongando-se as chuvas no dia 02 e dia 03 , que recebeu o segundo maior registro com 43,0 $\mathrm{mm}$, totalizando nos três primeiros dias 119,0 $\mathrm{mm}$. Ou seja, quase a metade dos eventos de chuvas nesse período ocorreu 15 dias antes da campanha, não comprometendo as coletas das amostras pelo baixo volume precipitado na bacia hidrográfica.

Em termos de totais anuais, a climatologia indica que em em média são contabilizados $1.950,0$ a 2.200,0 mm, sendo as áreas mais pluviosas na porção Sul da Flona Tapajós (Figura 3), onde também encontram-se as áreas mais declivosas com valores entre 18 e $24 \%$ de declividade (Figura 4), subdividindo a Flona em padrões topopluviais.

Reforça-se ainda, que na primeira quinzena de Dezembro, as chuvas se concentraram no primeiro quinquídio, representando cerca de 48,0\% dos eventos, sendo, o restante, distribuídas no quinto, quarto e sexto quinquídio do referido mês. Esses resultados corroboram com as avaliações de Martorano et al. (2004) que ressalntam que as chuvas em dezembro concentram-se na segunda quinzena, bem como aos resultados observados por Marengo (2005) em seus estudos climáticos na Amazônia. Esses dados reforçam que as coletas foram realizadas no período de menor oferta pluvial. Em períodos de baixo aporte de águas pluviais, espera-se que as variáveis hídricas expressem mudanças decorrentes de efeitos antrópicos, principalmente influenciada pela população ribeirinha.

Ao analisar as variáveis físico-hídricas foi possível observar que a água apresentou maior transparência ( 2 metros) próximo a comunidade do Tauarí com pH próximo de 5,5. Notou-se também que nas proximidades de Alter do Chão o $\mathrm{pH}$ apresentou mais próximo da neutralidade em relação aos demais pontos coletados (Figura 5). Os valores de coliformes totais foram mais elevados próximo à Taquara, seguido de Alter do Chão e os menores valores próximos ao Tauarí (Figura 6). Também em Alter do Chão os valores de oxigênio dissolvidos foram mais elevados (Figura 7). Por outro lado, a condutividade em Alter do Chão foi mais baixa em relação às demais localidades (Figura 8). 


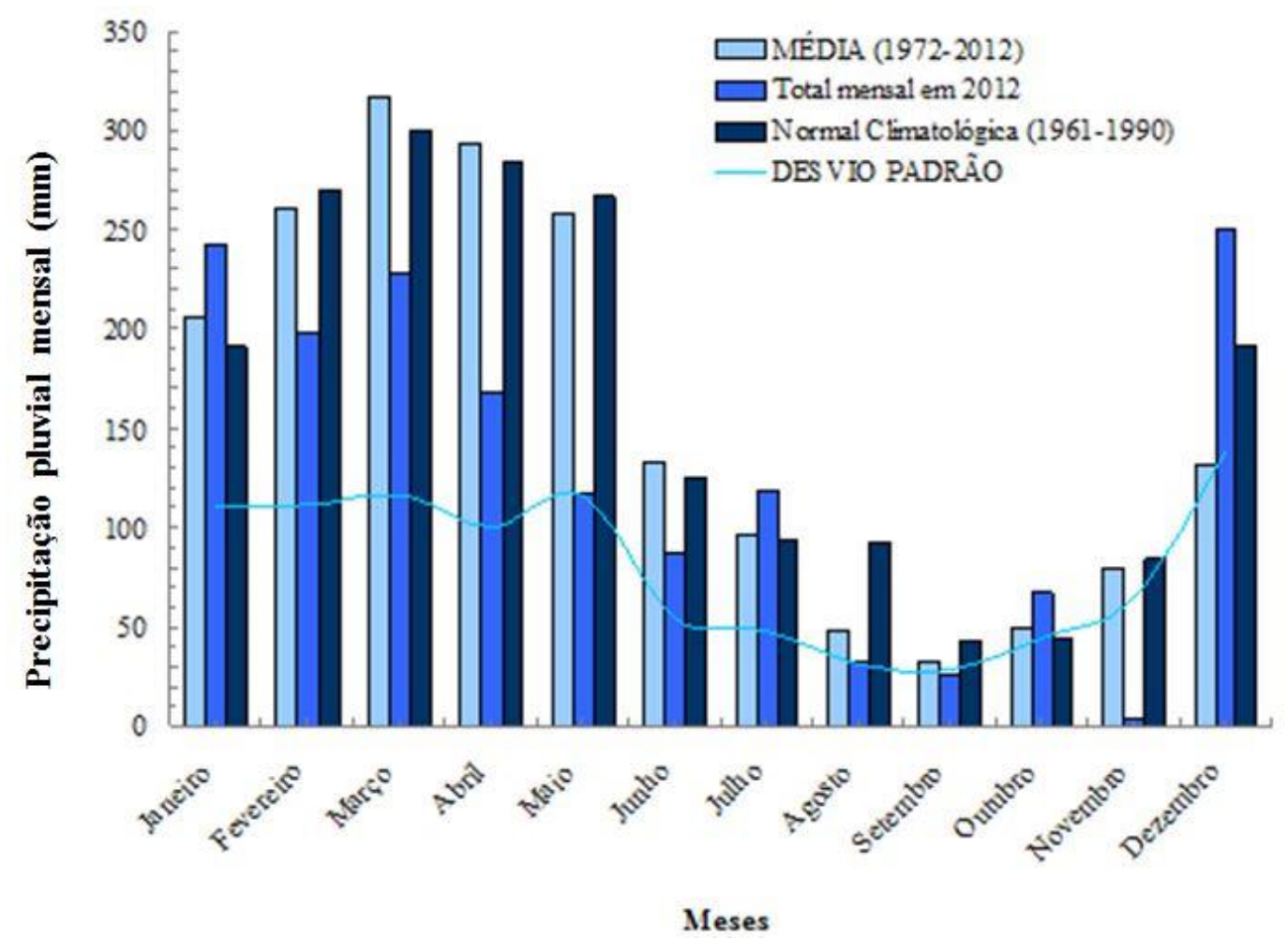

Figura 2. Precipitação pluvial mensal (mm) e desvio padrão em Belterra (PA) nos três períodos analisados (Normal climatológica - 1961 a 1990; Média - 1972 a 2012 e no ano de 2012).

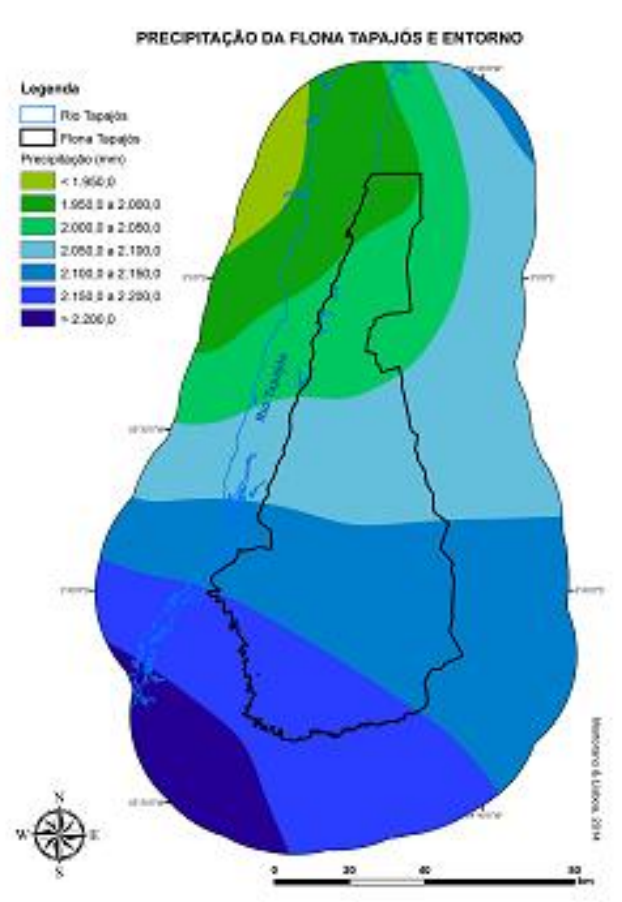

Figura 3. Precipitação pluvial anual $(\mathrm{mm})$ na Flona Tapajós e seu entorno.

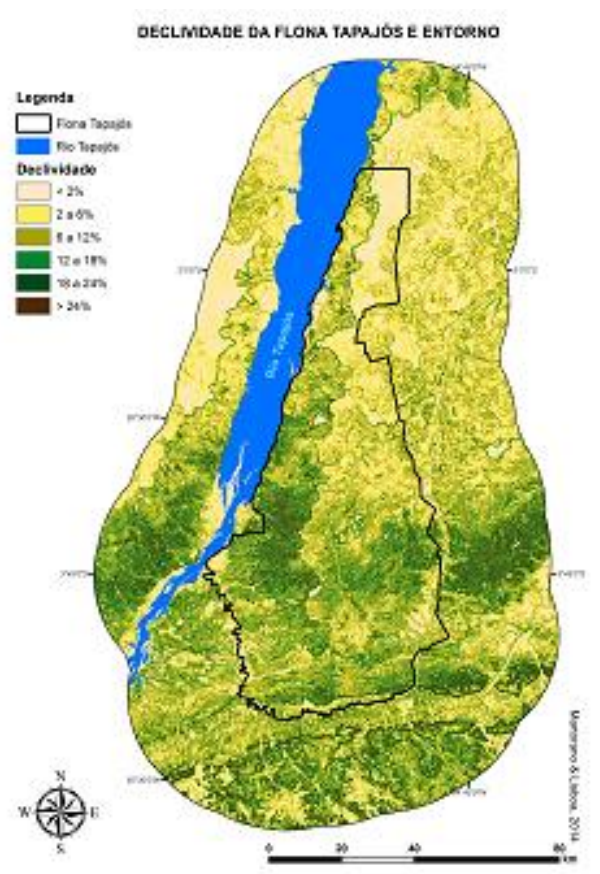

Figura 4. Classes de declividade na Flona Tapajós e seu entorno. 


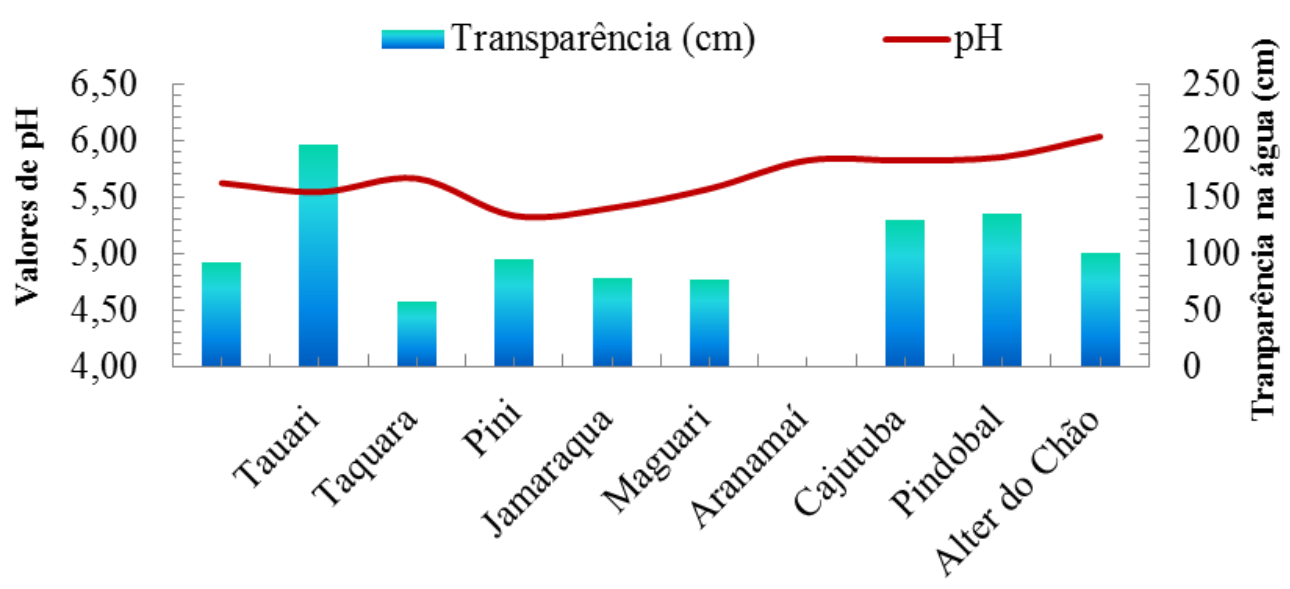

Figura 5. Valores de transparência e pH avaliadas no rio Tapajós na Flona Tapajós e seu entorno.

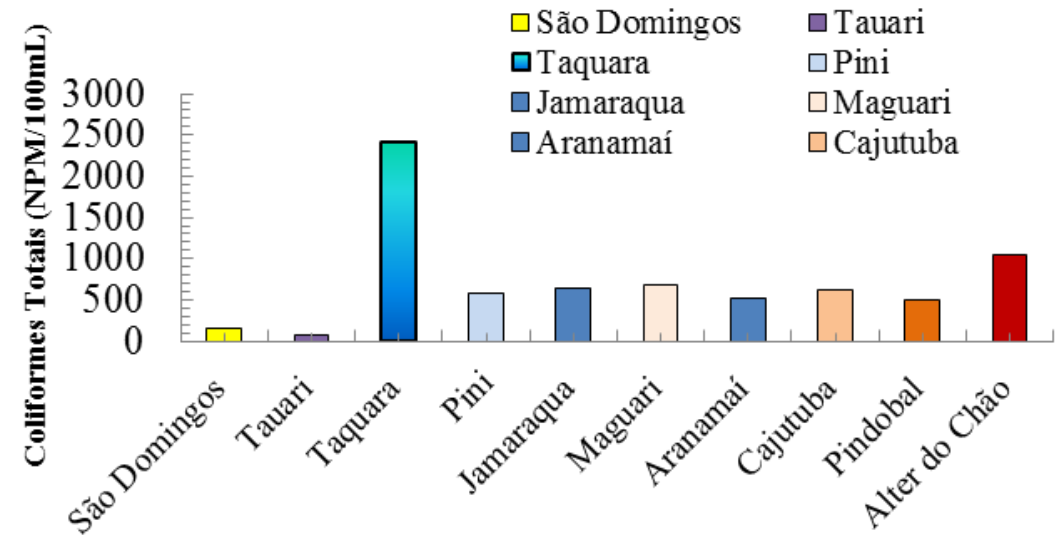

Figura 6. Coliformes Totais avaliadas no rio Tapajós na Flona Tapajós e seu entorno.

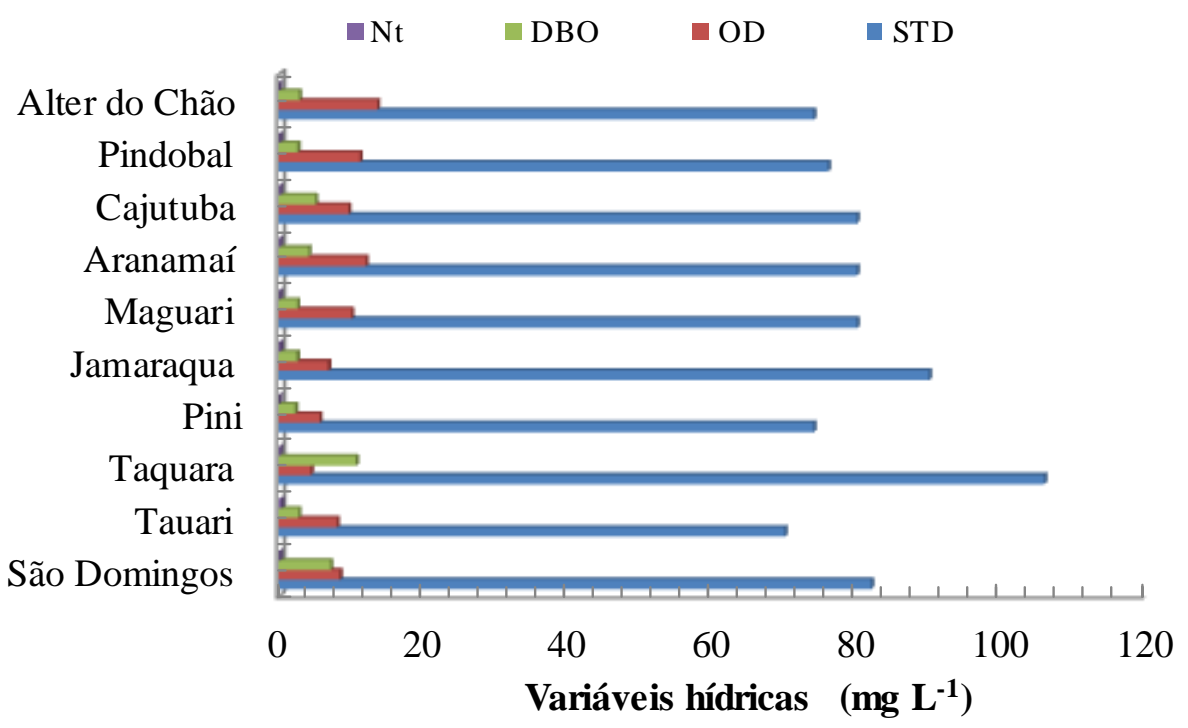

Figura 7. Variáveis hídricas (Nt, DBO, OD e SDT) avaliadas no rio Tapajós na Flona Tapajós e seu entorno. 


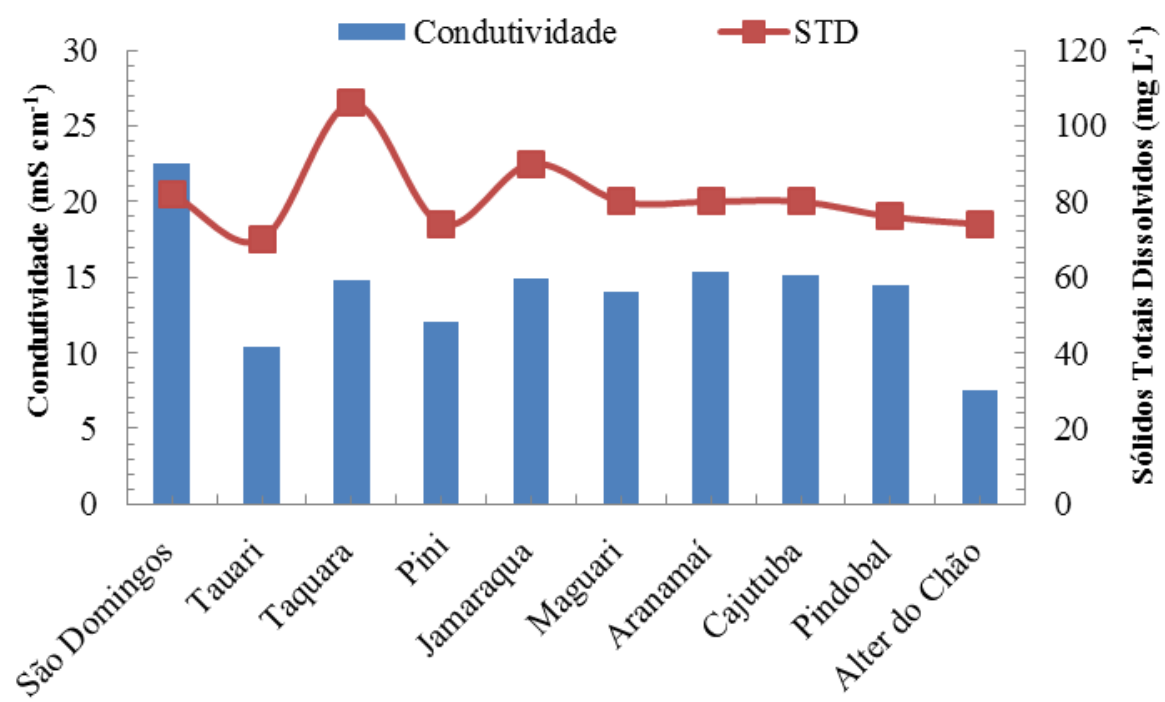

Figura 8. Condutividade e Sólidos Totais avaliados no rio Tapajós na Flona Tapajós e seu entorno.

Os resultados da qualidade hídrica superficial são apresentados na Tabela 2, na qual se observa que 7 dos 10 pontos de coleta, enquadram-se na faixa de boa qualidade de água para os padrões de comparação internacional, estabelecidos pela NSF. Comparados aos padrões nacionais, $80,0 \%$ enquadram-se na faixa de boa qualidade e $20,0 \%$ com ótima qualidade. Merece destaque o IQA das amostras próximas a Tauarí, com o valor de 85.

Os locais considerados com média qualidade de água, nas faixas da NSF foram São Domingos, Pindobal e Alter do Chão, que nas faixas da CETESB passaram para a condição de boa qualidade de água. Todavia, é importante ressaltar que para os padrões nacionais e internacionais o uso conservacionista na Flona Tapajós e seu entorno pode garantir a manutenção do potencial turístico, principalmente nos balneários ao longo dessa Unidade de Uso Sustentável, na Amazônia.

Tabela 2. Índice de Qualidade da Água (IQA) em localidades na Flona Tapajós e seu entorno.

\begin{tabular}{llll}
\hline Pontos (Comunidade) & IQA & NSF & CETESB \\
\hline F1 (São Domingos) & 64 & Médio & Boa \\
F2 (Tauari) & 85 & Bom & Ótima \\
F3 (Taquara) & 71 & Bom & Boa \\
F4 (Pini) & 72 & Bom & Boa \\
F5 (Jamaraquá) & 79 & Bom & Boa \\
F6 (Maguari) & 78 & Bom & Boa \\
F7 (Aranamaí) & 75 & Bom & Boa \\
F8 (Cajutuba) & 81 & Bom & Ótima \\
F9 (Pindobal) & 70 & Médio & Boa \\
F10 (Alter do Chão) & 70 & Médio & Boa \\
\hline
\end{tabular}


Utilizando-se as Análises de Agrupamento, é possível identificar pelo método de vizinhos mais próximos que as condições físico-químicas expressas em $\mathrm{pH}$, sólidos totais, fósforo, oxigênio dissolvidos, DBO, turbidez, temperatura da água, coliformes termotolerantes e totais, transparência, condutividade e IQA são semelhantes em Jamaraquá e Maguarí (Figura 9). Também, nas localidades de Pindobal e Alter do Chão as condições apresentam semelhanças físico-químicas e biológicas, entre si. Taquara e Aramanaí apresentaram bom IQA, mas pela análise de clusters suas características físico-químicas foram distintas, possivelmente devido aos efeitos da presença de coliformes termotolerantes e totais, os quais foram praticamente 5 vezes superiores aos valores obtidos em Aramanaí, bem como os de sólidos em suspensão que em Taquara foram cerca de 33,0\% a mais do que em Aramanaí, evidenciando possíveis perturbações no ambiente aquático investigado. Os valores de $\mathrm{pH}$ nos dez pontos coletados variaram de 5,33 (Pinim) a 6,03 (Alter do Chão). Caracterizado por Sioli (1984) como um rio de água clara, o rio Tapajós possui águas não muito ácidas. Porém, observou-se nos dados, $\mathrm{pH}$ abaixo da neutralidade, tendendo à acidez. Isto pode ser atribuído à decomposição de matéria orgânica que influencia a acidez natural das águas.

Alves et al. (2012) verificaram valores do IQA variando de "Ruim" e "Regular" no Rio Arari, na Ilha do Marajó, os quais provavelmente relacionados aos elevados níveis de coliformes fecais, baixas concentrações de oxigênio dissolvido e $\mathrm{pH}$ ácido. Os autores encontraram valores de $\mathrm{pH}$ no período chuvoso em média de 5,22 e no menos chuvoso de 6,28 no rio Arari.

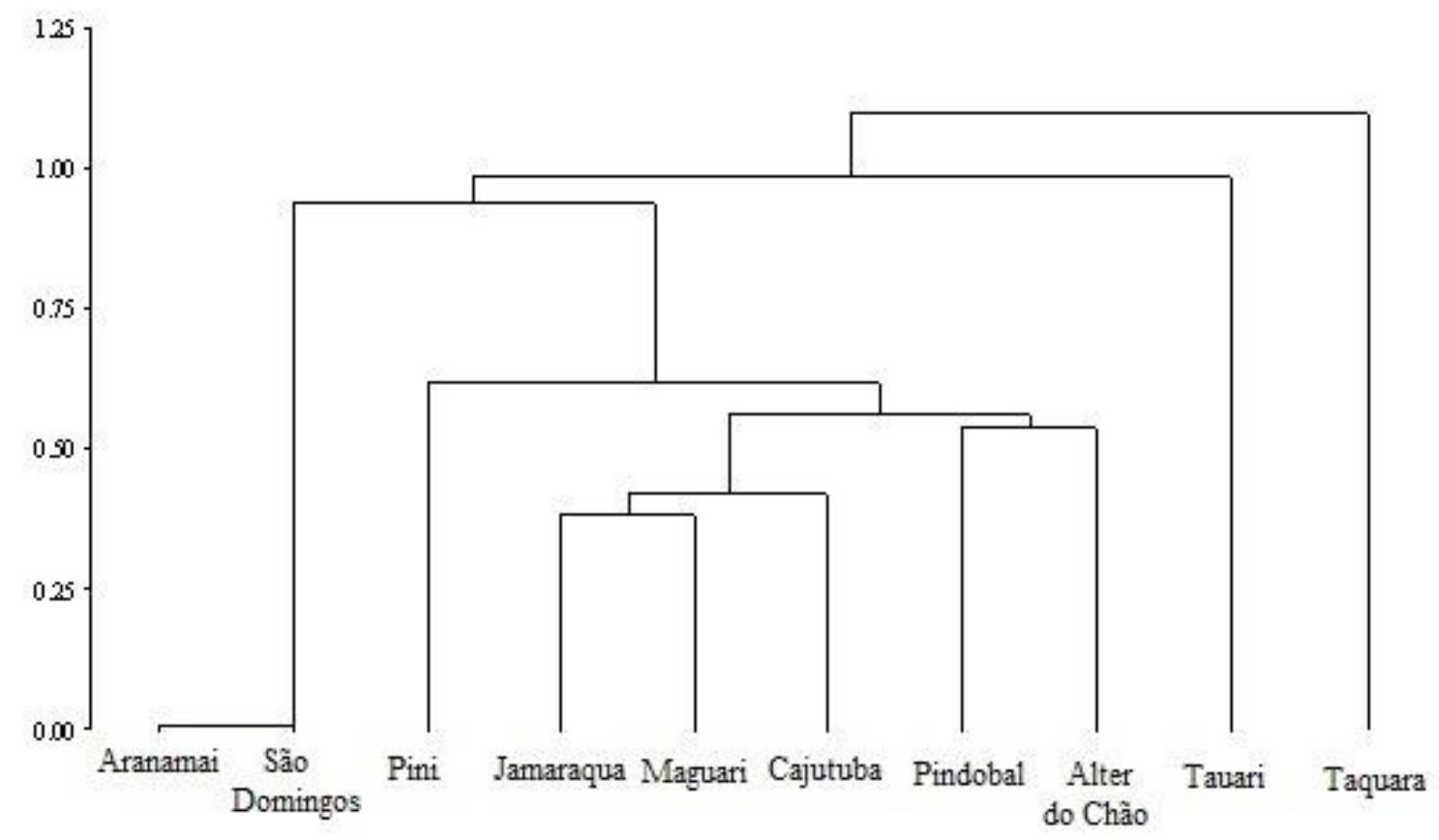

Figura 9. Análise de agrupamento pelo método do vizinho mais próximo nos 10 pontos de coletas na Flona Tapajós e seu entorno.

Os autovalores da matriz de correlação foram 5,$15 ; 3,44 ; 1,77 ; 1,28 ; 0,96 ; 0,22 ; 0,12$ e 0,05 ; e para os demais iguais a 0,00 . No total, esses somam 13,0 e representam a variação total das condições hídricas analisadas. Assim, o primeiro componente principal explica $(5,15 / 13) 100,0 \%$, ou seja, cerca de $40,0 \%$ da variância total. Similarmente, os outros componentes principais na respectiva ordem contam com $27,0 \%, 14,0 \%$ e o restante distribuído nos demais componentes principais da variância total. $\mathrm{O}$ primeiro componente principal é, portanto o mais importante. 
Os três primeiros componentes principais explicam juntos cerca de $80,0 \%$ do total da variação. Considerando um corte de $30,0 \%$, o primeiro componente principal pode ser representado por $\mathrm{CP}_{1}=0,399276 \times($ Sólidos Totais $)+0,367019 \times($ Demanda Bioquímica de Oxigênio $)+0,405918 \times($ Turbidez $)+0,329060 \times($ Coliformes Totais $)-0,356658 \times$ (Transparência). O segundo componente principal é $\mathrm{CP}_{2}=0,347818 \times(\mathrm{pH})+0,354770 \times$ (Fósforo total) $+0,349963 \times$ (Oxigênio Dissolvido) $-0,452938 \times$ (Nitrogênio Total ) $+0,456894 \times($ Coliformes Termotolerantes) $-0,304178 \times$ (IQA). O terceiro componente principal é $\mathrm{CP}_{3}=0,454304 \times($ Temperatura da água $)+0,454460 \times($ Coliformes Totais) $0,475798 \times($ Condutividade $)+0,404885 \times($ IQA $)$.

$\mathrm{O} \mathrm{CP}_{1}$ indica um contraste existente entre sólidos totais, demanda bioquímica de oxigênio, turbidez e coliformes totais com a transparência da água. Portanto, os locais São Domingos e Taquara são caracterizados por apresentar altos índices de efeitos positivos dessa equação e baixo índice para a transparência da água. $O$ gráfico Biplot apresentado na Figura 10a corrobora com o que esta sendo discutido. Por outro lado, Tauari, por exemplo, destaca-se pela transparência da água e por apresentar baixos índices de sólidos totais, demanda bioquímica de oxigênio, turbidez e coliformes totais.

No $\mathrm{CP}_{2}$ observa-se um contraste entre $\mathrm{pH}$, oxigênio dissolvido, fósforo total, coliformes termotolerantes com o nitrogênio total e o índice da qualidade da água. Nota-se que os locais Alter do Chão e Pindobal possuem altos índices de $\mathrm{pH}$, oxigênio dissolvido, fósforo total e coliformes termotolerantes localizando na parte positiva do eixo do $\mathrm{CP}_{2}$. Esses mesmos locais apresentam índices mais baixos para nitrogênio total e o índice da qualidade da água. Tauari e Jamaraqua ao contrário de Alter do Chão e Pindobal possuem índices mais elevados para nitrogênio total e o IQA localizando-se na parte negativa do eixo do $\mathrm{CP}_{2}$ na Figura 10a.

O CP3 mede o contraste entre temperatura, coliformes totais e índice de qualidade da água com a condutividade. Os locais onde foram feitas as análises em Pini e São Domingos foram os que apresentaram altos índices para condutividade e índices baixos para temperatura, coliformes totais e índice de qualidade da água. Nessa mesma equação, destaca-se Cajutuba, Taquara, Jamaraqua e Tauarí por apresentarem valores mais elevados de temperatura, coliformes totais e índice de qualidade da água e baixos índices para condutividade. O gráfico Triplot apresentado na Figura 10b confirma essas relações.

Destacam-se as comunidades de Maguari, Pini e Cajutuba por apresentarem uma média geral em relação às demais variáveis avaliadas, indicando que essas comunidades ficam no centro do gráfico Biplot, apontando o ponto médio.

O Biplot Figura 10a e o Triplot ilustrado na Figura 10b evidenciam a contribuição de cada local onde foram realizadas as coletas e cada variável por um vetor [ $\mathrm{pH}$, Sólidos Totais ( $\left.\mathrm{mg} \mathrm{L}^{-1}\right)$, Fósforo total $\left(\mathrm{mg} \mathrm{L}^{-1}\right)$, Oxigênio Dissolvido $\left(\mathrm{mg} \mathrm{L}^{-1}\right)$, Demanda Bioquímica de Oxigênio $\left(\mathrm{mg} \mathrm{L}^{-1}\right)$, Turbidez (UNT), Temperatura da água $\left({ }^{\circ} \mathrm{C}\right)$, Nitrogênio Total $\left(\mathrm{mg} \mathrm{L}^{-1}\right)$, Coliformes Termotolerantes e Totais (NMP $\left.100 \mathrm{~mL}^{-1}\right)$, Transparência $(\mathrm{cm})$, Condutividade $\left(\mu \mathrm{S} \mathrm{cm}^{-1}\right)$ e IQA], permitindo assim, avaliar as semelhanças ou não, entre os mesmos. Pelo Biplot, representado na Figura 10a, verificou-se uma forte correlação positiva entre as variáveis: Turbidez, Demanda Bioquímica de Oxigênio e Sólidos Totais.

Também, existe uma correlação entre Temperatura da água e Oxigênio Dissolvido. Houve correlações negativas entre as variáveis IQA e Fósforo total, assim como, Transparência e Coliformes Totais. Todas essas correlações puderam ser observadas também na matriz de correlação (não apresentada nesse trabalho). Em se tratando das análises de componentes principais, representadas na Figura 10b Triplot, estas reforçam que os pontos com alta presença de coliformes termotolerantes em Alter do Chão e Pindobal, verificada entre $\mathrm{CP}_{2}$ e $\mathrm{CP}_{3}$, são diametralmente opostos aos valores de Turbidez, observados em Jamaraquá e Taquara. No ponto próximo a comunidade de Tauarí, os valores de Oxigênio Dissolvido foram os mais elevados e a coluna de transparência, verificada in situ, atingiu 
quase dois metros, reforçando o estado de conservação mais expressivo nas variáveis hídricas investigadas, localizados próximo ao eixo $\mathrm{CP}_{3}$.

Ainda analisando o gráfico Biplot, pela proximidade do ponto, consolida-se a forte correlação da comunidade Tauarí com o eixo do IQA. Pode-se ponderar o fato de nesta região não ocorrer o acesso para uso turístico, refletindo, portanto, nas melhores condições hídricas, em relação aos demais locais avaliados na Flona e seu entorno.
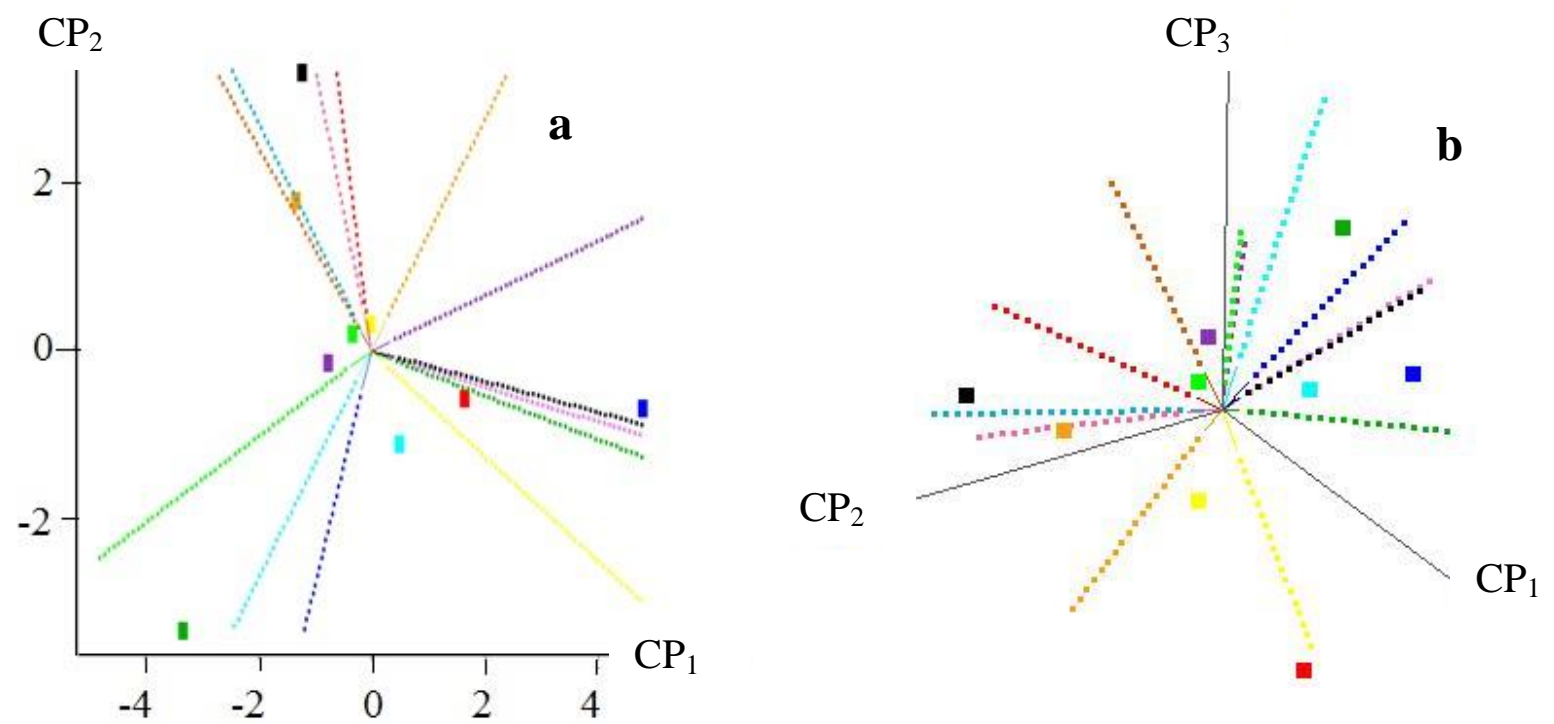

Legenda:

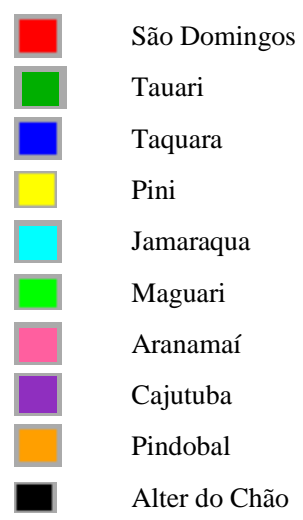

$\mathrm{pH}$
Sólidos Totais $\left(\mathrm{ml} \mathrm{L}^{-1}\right)$
Fósforo Total $\left(\mathrm{ml} \mathrm{L}^{-1}\right)$
Oxigênio Dissolvido. $\left(\mathrm{ml} \mathrm{L}^{-1}\right)$
Demanda Bioquímica de Oxigênio $\left(\mathrm{ml} \mathrm{L}^{-1}\right)$
Turbidez $(\mathrm{UNT})$

Figura 10. a) Biplot dos escores nos dez pontos de coletas dos dois componentes principais mais importantes referentes as 13 variáveis do estudo; b) Triplot dos escores dos três componentes principais mais importantes referentes as 13 variáveis do estudo nos dez pontos de coletas.

Entre as 10 localidades avaliadas os maiores valores de DBO foram observados em Taquara, indicando que há maior incremento de matéria orgânica e, portanto, possíveis comprometimentos no equilíbrio ecossistêmico, como, por exemplo, a oferta de pescado que é base da alimentação de comunidades ribeirinhas, na Amazônia.

\section{CONCLUSÕES}

Com base nos resultados obtidos conclui-se:

O ritmo climático evidenciou que o mês de Dezembro marca a fase intermediária entre o fim do período de menor oferta pluvial e o início das chuvas;

Chove mais na porção sul onde também ocorrem as áreas mais declivosas apresentando um padrão topo pluvial diferenciado na Flona Tapajós e seu entorno; 
A análise de indicadores hídricos pode mostrar possíveis ameaças à manutenção de bens e serviços que o rio Tapajós oferece às populações;

O IQA pode ser um dos índices de avaliação em corpos hídricos sob a influência de Unidades de Uso Sustentável como é o caso da Flona Tapajós;

Nas proximidades da comunidade do Tauarí a coluna de transparência da água, o IQA e a baixa ocorrência de coliformes termotolerantes evidenciam o estado de conservação refletido nas variáveis hídricas avaliadas;

As águas próximas aos balneários de Alter do Chão e Pindobal apontam efeitos de antropização devido à alta presença de coliformes termotolerantes em relação aos demais pontos analisados;

Nos balneários (Alter do Chão e Pindobal), apesar dos valores estarem dentro dos limites aceitáveis com IQA nas faixas entre médio e bom, alerta-se para cuidados quanto ao uso sustentável e para a manutenção do seu potencial turístico;

Os valores elevados de DBO em Taquara indicam que há maior disponibilidade de incremento de matéria orgânica, o que pode induzir ao completo esgotamento de oxigênio na água e comprometer a vida aquática;

Ações conservacionistas necessitam ser aplicadas em áreas no entorno da Flona Tapajós para garantir bens e serviços ambientais que o rio Tapajós presta à sociedade como, por exemplo, o fornecimento de água com índices de alta qualidade para uso alimentar, higiene e manutenção do potencial balneário na região;

Os corpos hídricos são sensíveis às alterações no uso e cobertura do solo e podem evidenciar possíveis alterações capazes de ameaçar o equilíbrio em áreas de uso conservacionista como é o caso da Floresta Nacional do Tapajós; e,

Espera-se que os resultados obtidos nesta pesquisa possam subsidiar avaliações de uso conservacionista em bacias hidrográficas para garantir os serviços ecossistêmicos prestados pelas comunidades em áreas legalmente protegidas na Amazônia.

\section{AGRADECIMENTOS}

Os autores expressam seus agradecimentos à Coordenação de Aperfeiçoamento de Pessoal de Nível Superior (CAPES) pelo financiamento da bolsa de mestrado da primeira autora; à Universidade do Estado do Pará e ao Programa de Mestrado em Ciências Ambientais; à coordenação e à equipe do Projeto ROBIN; à Embrapa Amazônia Oriental; ao Núcleo Médio Amazonas da Embrapa; ao Instituto Chico Mendes de Conservação da Biodiversidade (ICMBio) de Santarém e ao $4^{\circ}$ Grupamento Bombeiro Militar de Santarém (Pará).

\section{REFERÊNCIAS}

AMERICAN PUBLIC HEALTH ASSOCIATION - APHA. Standard methods for examination of water and wastewater. 21. ed. Washington, 2005. 4358 p.

ALVES, I. C. C.; EL-ROBRINI, M.; SANTOS, M. L. S.; MONTEIRO, S. M.; BARBOSA, L. P. F.; GUIMARÃES, J. T. F. Qualidade das águas superficiais e avaliação do estado trófico do Rio Arari (Ilha de Marajó, norte do Brasil). Acta Amazônia, v. 42, n. 1, p. 115-124, 2012. http://dx.doi.org/10.1590/S0044-59672012000100014

ARTAXO, P. Opportunities for research in global changes in the field of chemistry. Journal of the Brazilian Chemical Society, v. 18, n. 2, 2007. http://dx.doi.org/10.1590/S010350532007000200001 
BRASIL. Decreto $\mathrm{n}^{\circ}$ 73.684, de 19 de fevereiro de 1974. Cria a Floresta Nacional do Tapajós e dá outras providências. Diário Oficial [da] União, Seção 1, p. 1987, 20 fev. 1974.

. Lei 12.678, de 25 de junho de 2012. Dispõe sobre alterações nos limites dos Parques Nacionais da Amazônia, dos Campos Amazônicos e Mapinguari, das Florestas Nacionais de Itaituba I, Itaituba II e do Crepori e da Área de Proteção Ambiental do Tapajós; altera a Lei no 12.249, de 11 de junho de 2010; e dá outras providências. Diário Oficial [da] União, Seção 1, 26 jun. 2012.

COMPANHIA DE TECNOLOGIA E SANEAMENTO AMBIENTAL - CETESB. Relatório de qualidade das águas interiores no Estado de São Paulo 2005. São Paulo, 2006.

Guia nacional de coleta e preservação de amostras: água, sedimento, comunidades aquáticas e efluentes líquidos. Brasília: CETESB; ANA, 2011. 326 p.

.Águas superficiais: variáveis de qualidade de água. São Paulo, 2012. Disponível em: <http://www.cetesb.sp.gov.br>. Acesso em 01 ago. 2012.

CONSELHO NACIONAL DO MEIO AMBIENTE - CONAMA (Brasil). Resolução no 357, de 17 de março de 2005. Brasília, 2005.

FEARNSIDE, P. M. A água de São Paulo e a floresta amazônica. Ciência Hoje, v. 34, p. 63 $65,2004$.

Serviços ambientais provenientes de florestas intactas, degradadas e secundárias na Amazônia brasileira. In: PERES, C. A.; GARDNER T. A.; BARLOW, J.; VIEIRA, I. C. G. (eds.). Conservação da biodiversidade em paisagens antropizadas do Brasil. Curitiba: Editora da Universidade Federal do Paraná, 2013. p. 29-62.

FERREIRA, D. F. Estatística multivariada. 2. ed. Lavras: Editora UFLA, 2011. v. 1. 675 p.

GATTI, S.; BREY, T.; MULlER, W. E. G.; HEILMAYER, O.; HOLST, G. Oxygen microoptodes: a new tool for oxygen measurements in aquatic animal ecology. Marine Biology, v. 40, n. 6, p. 1075-1085, 2002. http://dx.doi.org/10.1007/s00227-002-0786-9

INSTITUTO BRASILEIRO DE GEOGRAFIAS E ESTATÍSTICAS - IBGE. Banco de dados agregados ao sistema IBGE de recuperação automática (SIDRA). 2013. Disponível em: <http://www.ibge.gov.br>. Acesso em: 04 fev. 2014.

INSTITUTO BRASILEIRO DO MEIO AMBIENTE E DOS RECURSOS NATURAIS RENOVÁVEIS - IBAMA. Floresta Nacional do Tapajós: plano de manejo: vol. I informações gerais. 2004. Disponível em: http://www.icmbio.gov.br/portal/images /stories/imgs-unidades-coservacao/flona_tapajoss.pdf. Acesso em: set. 2014.

INSTITUTO NACIONAL DE METEOROLOGIA - INMET (Brasil). Normais climatológicas do Brasil. Brasília, 2009. 465p.

MANLY, B. F. J. Multivariate statistical methods a primer. 3. ed. New York: Chapman \& Hall, 2004. 215p.

ANZATTO, C. V.; FREITAS JUNIOR, E.; PERES, J. R. R. Uso agrícola dos solos brasileiros. Rio de Janeiro: Embrapa Solos, 2002. 174 p.

MARENGO, J. Characteristics and spacio-temporal variability of the Amazon river basin water budget. Climate Dynamics, v. 24, n. 1, p. 11-22, 2005.

http://dx.doi.org/10.1007/s00382-004-0461-6 
MARTORANO, L. G.; NECHET, D.; MANZATTO, C. V.; REBELLO, E.; BERTOLOSSI, R. Pluviometric variations as subsidiary information for agricultural planning in the Amazon. In: INTERNATIONAL SOIL CONSERVATION ORGANIZATION CONFERENCE - ISCO, 13., 2004, Brisbane. Papers... Disponível em: http://tucson.ars.ag.gov/isco/isco13/PAPERSM-Q/MARTORANO.pdf. Acesso em: set. 2014.

MARTORANO, L. G.; BERGAMASCHI, H.; FARIA, R. T.; DALMAGO, G. A. Decision Strategies for Soil Water Estimations in Soybean Crops Subjected to No-Tillage and Conventional Systems, in Brazil. In: INTECH. Problems, perspectives and challenges of agricultural water management. 1 ed. 2008. Disponível em: Decision strategies_for_soil_water_estimations_in_soybean_crops_subjected_to_no_tillage_and_ conventional_systems_in_brazil. Acesso em: set. 2014.

MINGOTI, S. A. Análise de dados através de métodos de Estatística Multivariada: uma abordagem aplicada. Belo Horizonte: Editora UFMG, 2005. 295p.

PRADO, B. P.; NOVO, M. L. M. N. Análise espaço-temporal da relação do estado trófico do reservatório de Barra Bonita (SP) com o potencial poluidor da Bacia hidrográfica. São José dos Campos: INPE, 2006.

RUDORFF, C. M.; NOVO, E. M. L. M.; GALVÃO, L. S. Spectral mixture analysis for water quality assessment over the Amazon foodplain using Hyperion/EO-1 images. Revista Ambient. Água, v. 1, n. 2, p. 65-79, 2006. http://dx.doi.org/10.4136/ambi-agua.13

SAS INSTITUTE INC. SAS statistical software. Release 9.2. Cary, 2008.

SILVA, A. E. P.; ANGELIS, C. F.; MACHADO, L. A. T.; WAICHAMAN, A. V. Influência da precipitação na qualidade da água do Rio Purus. Acta Amazonia, v. 38, n. 4, p. $733-$ 742, 2008. http://dx.doi.org/10.1590/S0044-59672008000400017

SIOLI, H. The Amazon: limnology and landscape ecology of a migth tropical river and it's basin. Monographie Biologicae, v. 56, 1984.

SIQUEIRA, G. W.; APRILE, F.; MIGUÉIS A. M. Diagnóstico da qualidade da água do rio Parauapebas (Pará - Brasil). Acta Amazonia, v. 42, n. 3, p. 413-422, 2008. http://dx.doi.org/10.1590/S0044-59672012000300014

SISTEMA NACIONAL DE UNIDADES DE CONSERVAÇÃO SNUC. Texto da Lei $\mathbf{9 . 9 8 5}$ de 18 de julho de 2000 e vetos da presidência da República ao PL aprovado pelo Congresso Nacional. 2. ed. São Paulo: Conselho Nacional da Reserva da Biosfera da Mata Atlântica, 2002. 76 p.

VON SPERLING, M. Estudos e modelagem da qualidade da água de rios. Belo Horizonte: DESA, 2007. $588 \mathrm{p}$. 